\title{
Image Orientation Incorrect
}

National Cancer Institute

\section{Source}

National Cancer Institute. Image Orientation Incorrect. NCI Thesaurus. Code C62887.

Problem associated with an incorrect image orientation on the device display. 